\title{
Correction to: Process parameter selection for selective laser melting of Ti6Al4V based on temperature distribution simulation and experimental sintering
}

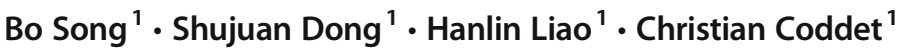 \\ Published online: 17December 2019 \\ (C) Springer-Verlag London Ltd., part of Springer Nature 2019
}

\section{Correction to: Int J Adv Manuf Technol (2013) 61:967-974} https://doi.org/10.1007/s00170-011-3776-6

The authors regret to inform that a missing reference [27] should be marked in the caption of Fig. 6(a) in the published paper.

[27] B. Song, S. J. Dong, B. C. Zhang, H. L. Liao, C. Coddet, Mater Des 35 (2012) 120-125.

The reference number behind [27] would be incremental, and there are 30 references in total.

Author would like to apologize for the inconvenience caused.

The online version of the original article can be found at https://doi.org/ 10.1007/s00170-011-3776-6

Bo Song

bo.song@utbm.fr

\footnotetext{
LERMPS, Université de Technologie de Belfort-Montbéliard, Site de Sévenans, 90010 Belfort, France
} 